\title{
Lansky Performance Status 20
}

National Cancer Institute

\section{Source}

National Cancer Institute. Lansky Performance Status 20. NCI Thesaurus. Code C70540.

Often sleeping; play entirely limited to very passive activities. 